\title{
Risk Factors and Surgical Treatment for Recurrent Lumbar Disc Prolapse: A Review of the Literature
}

\author{
Bharat R. Dave, Devanand Degulmadi, Ajay Krishnan, Shivanand Mayi \\ Stavya Spine Hospital and Research Institute, Ahmedabad, India
}

We aim to present the current evidence on various risk factors and surgical treatment modalities for recurrent lumbar disc herniation (rLDH). Using PubMed, a literature search was performed using the Mesh terms "recurrent disc prolapse," "herniated lumbar disc," "risk factors," and "treatment." Articles that were published between January 2010 and May 2017 were selected for further screening. A search conducted through PubMed identified 213 articles that met the initial screening criteria. Detailed analyses showed that 34 articles were eligible for inclusion in this review. Sixteen articles reported the risk factors associated with rLDH. Decompression alone as a treatment option was studied in seven articles, while 11 articles focused on different types of fusion surgery (anterior lumbar interbody fusion, posterior lumbar interbody fusion, open transforaminal lumbar interbody fusion [TLIF], and minimally invasive surgery-TLIF). Management of the rLDH requires consideration of the possible risk factors present in individual patients before primary and at the time of second surgery. Both, minimally invasive and conventional open procedures are comparably effective in relieving leg pain, and minimally invasive techniques offer advantage over the other technique in terms of tissue sparing. Non-fusion surgeries involve the risk of lumbar disc herniation re-recurrence, and the patient may require a third (fusion) surgery.

Keywords: Recurrent disc prolapse; Herniated lumbar disc; Risk factors; Lumbar interbody fusion

\section{Introduction}

Surgical intervention for lumbar disc herniation (LDH) has yielded one of the most promising results; however, it involves complications. Recurrent disc herniation is one of the complications of primary surgery. The reported incidence of recurrent disc herniation in the literature ranges from $0.5 \%-23 \%[1,2]$. Many modifiable and nonmodifiable risk factors have been mentioned in various studies [1-17]. Although various surgical modalities of treatment have been practiced in treating recurrent disc herniation, significant heterogeneity exists among surgeons [18-35]. The reasons for diverse opinions may be attributed to clinical and biomechanical variables involved in the prognosis following the surgery. Knowledge about the various risk factors and surgical techniques would help in better planning of treatment of primary LDH. This review article presents the current evidence of various risk factors and surgical treatment modalities for recurrent disc herniation.

\section{Search Methodology and Selection}

A literature search was performed by two reviewers (BRD and DD) to collect articles published in PubMed using the $\mathrm{MeSH}$ terms "recurrent disc prolapse," "herniated lumbar

Received Nov 27, 2018; Revised Mar 8, 2019; Accepted Mar 10, 2019

Corresponding author: Devanand Degulmadi

Stavya Spine Hospital and Research Institute, Mithakali, Ahmedabad 380007, India

Tel: +91-7874444091, Fax: +91-079-2656-5657, E-mail: drdanand@yahoo.co.in 
disc," "risk factors," and "treatment." Articles published between January 2010 and May 2017 were selected for further screening. Additional manual searches were performed using the references in the selected articles that were relevant to recurrent lumbar disc herniation (rLDH). Disagreements were resolved with consensus, and a third reviewer was consulted, if necessary.

\section{Inclusion and exclusion criteria}

Randomized control studies, observational studies, and case series were included in this review. There was no preference for the type of study (retrospective/prospective). Case reports, review articles, and technical reports were excluded. Studies with a sample size $<10$ were not included in the review. All the articles were screened for titles and abstract. Selected articles were studied in detail, and the relevant data were recorded.

\section{Data extraction and recording}

The following data were recorded: (1) study ID: including the author name, journal name, and year of publication; (2) study design/type: retrospective/prospective; (3) study sample size: number of patients; (4) risk factors; (5) surgical intervention: decompression alone (conventional discectomy, micro lumbar discectomy [MLD], micro en- doscopic discectomy [MED]; fusion (anterior lumbar interbody fusion [ALIF], posterior lumbar interbody fusion [PLIF], transforaminal lumbar interbody fusion [TLIF], open/minimally invasive surgery [MIS]-TLIF]); (6) clinical results; and (7) follow-up duration.

As the analysis was based on previously published studies, no ethical committee approval or patient consent was required.

\section{Results}

The PubMed search resulted in the identification of 213 articles that met the initial screening criteria. Detailed analyses identified 34 articles that were eligible for inclusion in this review. Sixteen articles reported risk factors associated with rLDH. Decompression alone as a treatment option was studied in seven articles, and 11 articles focused on the different types of fusion surgery (ALIF, LIF, open TLIF, or MIS-TLIF).

\section{Risk factors (Table 1)}

1) Age

Age $<40$ years was shown to be associated with recurrence in the studies by Yurac et al. [3] and Chang et al. [4]. Few studies showed no statistical significance between age and recurrence [1,5-7]. In contrast, Yao et al. [9] found that

Table 1. Studies showing the recurrence rate and associated risk factors of rLDH

\begin{tabular}{|c|c|c|c|c|c|c|}
\hline Author & Year & Study design & $\begin{array}{l}\text { Sample } \\
\text { size }\end{array}$ & $\begin{array}{l}\text { Mean } \\
\text { follow-up }\end{array}$ & $\begin{array}{l}\text { Recurrence } \\
\text { rate }(\%)\end{array}$ & Risk factor \\
\hline Aizawa et al. [1] & 2012 & Retrospective & 186 & $12 \mathrm{mo}$ & 0.5 & Male, surgery at young age \\
\hline Yurac et al. [3] & 2016 & Case control & 1,028 & $16 \mathrm{yr}$ & 7.8 & $<30$ years, subligamentous disc herniation \\
\hline Chang et al. [4] & 2016 & Retrospective & 58 & $24.6 \mathrm{mo}$ & 10.3 & $<40$ years with scoliosis \\
\hline Shimia et al. [5] & 2013 & Retrospective & 160 & $18 \mathrm{mo}$ & & Male, taller height, heavy work, smoking \\
\hline Moliterno et al. [6] & 2010 & Retrospective & 217 & $19.1 \mathrm{mo}$ & 9.5 & Low BMI (non obese) \\
\hline Kim et al. [7] & 2015 & Retrospective & 467 & $51.1 \mathrm{mo}$ & & $\begin{array}{l}\text { Male, large annular defect, moderate disc degenera- } \\
\text { tion, low iliac crest height }\end{array}$ \\
\hline Meredith et al. [8] & 2010 & Retrospective & 75 & $24 \mathrm{mo}$ & 10.7 & Obesity \\
\hline Yao et al. [9] & 2016 & Retrospective & 111 & $24 \mathrm{mo}$ & & $>50$ years, obesity, Modic changes \\
\hline Miwa et al. [10] & 2015 & Prospective & 298 & $39 \mathrm{mo}$ & 10.7 & Smoking, lifting weight \\
\hline Motsumoto et al. [11] & 2013 & Prospective & 344 & $3.6 \mathrm{yr}$ & & Caudally migrated disc \\
\hline Yaman et al. [12] & 2017 & Retrospective & 600 & $10.6 \mathrm{mo}$ & 7.3 & $\begin{array}{l}\text { Preoperative higher disc height, high BMI, Modic } \\
\text { changes }\end{array}$ \\
\hline Quah et al. [13] & 2014 & Retrospective & 283 & $6 \mathrm{mo}$ & 9.5 & Obesity not a predictor of rLDH \\
\hline
\end{tabular}

$\mathrm{rLDH}$, recurrent lumbar disc herniation; $\mathrm{BMI}$, body mass index. 
age $>50$ years is a strong risk factor for the development of rLDH.

2) Sex

Risk of recurrence was significantly associated with male sex, as reported by Shimia et al. [5] and Kim et al. [7]. Other studies have shown no association between sex and recurrence $[1,6-8,10,11]$.

\section{3) Body mass index}

Non-obese patients (those with normal or low body mass index $[\mathrm{BMI}]$ ) appear to be at a greater risk of recurrence [6]. In contrast, obesity $\left(\mathrm{BMI} \geq 30 \mathrm{~kg} / \mathrm{m}^{2}\right)$ was reported as a strong predictor of rLDH by Meredith et al. [8] (33.6 55.1 $\mathrm{kg} / \mathrm{m}^{2}$ ), and the average BMI of those with $\mathrm{rLDH}$ was higher $\left(24.8 \pm 0.8 \mathrm{~kg} / \mathrm{m}^{2}\right)$ than that of those without $\mathrm{rLDH}$ $\left(23.8 \pm 1.3 \mathrm{~kg} / \mathrm{m}^{2}\right)[12]$. Other studies did not report a significant relationship of rLDH with high BMI $[1,5,7,10,13]$.

4) Disc height

Patients with $\mathrm{rLDH}$ had a higher preoperative disc height $(19.1 \pm 4.6 \mathrm{~mm})$ than those without $\mathrm{rLDH}(15.0 \pm 3.3 \mathrm{~mm})$ [12].

\section{5) Smoking}

The habit of smoking was significantly more common in those with rLDH [5]. Miwa et al. [10] analyzed 32 reoperation cases out of 298 primary discectomy cases and concluded that the smoker group showed an $18.5 \%$ higher recurrence rate than the non-smoker group. Other studies did not find any association between smoking and $\operatorname{rLDH}[7,8]$.

\section{6) Occupation}

Lifting weights as part of professional work was significantly associated with $\mathrm{rLDH}$ [10]. In contrast, Meredith et al. [8] concluded that manual laborers did not have a significantly higher risk of recurrence than those who were not involved in manual labor. Based on their study, Shimia et al. [5] concluded that surgeons should advice their patients to limit hard laborious work to prevent $\mathrm{rLDH}$.

\section{7) Modic changes}

Recently, Modic changes have been related to the risk of recurrence. Yao et al. [9] have identified Modic changes as a significant risk factor. Modic endplate changes were statistically higher in the recurrent group than in the nonrecurrent group $(p=0.032)$ in the study by Yaman et al.
[12].

8) Type of lumbar disc herniation

The nature of primary LDH plays a role in recurrence; higher preoperative intervertebral disc space significantly influenced recurrence $(p<0.001)$, as reported by Yaman et al. [12]. Sub ligamentous or trans ligamentous disc herniation, caudal migration of the herniated disc, and large annular defect are believed to increase the chances of recurrence in different studies $[7,11,14]$.

\section{9) Type of primary surgery}

Based on his study, Teli et al. [15] concluded that MED cannot be recommend as a routine approach for treating $\mathrm{LDH}$ because of the higher rates of complications that included dural injury, root injury, and recurrence. Most reoperations after lumbar disc discectomy presented during the $0-0.5$-year and 1-5-year periods following the primary surgery in most recurrences after primary lumbar disc discectomy presented during the 0-0.5-year followup in minimally invasive endoscopic discectomy group and 1-5-year following minimally invasive endoscopic discectomy [16]. Park et al. [17] found no significant difference in the rLDH incidence of the herniotomy and conventional discectomy groups.

\section{Surgical interventions (Table 2)}

\section{1) Conventional discectomy}

Jung et al. [14] and Ahsan et al. [18] reported their results of conventional discectomy for $\mathrm{rDH}[14,18]$. Both the studies reported excellent to good relief in 78\%-96\% of the patients. Dural tear was the most commonly reported complication followed by superficial wound infection. One patient with poor outcome required revision surgery.

\section{2) Microendoscopic discectomy}

Four studies reported their outcomes regarding recurrence in patients who underwent MED. All four studies reported good to excellent outcomes in $60 \%-90 \%$ of the patients, as per Mcnab's criteria. Significant improvement was observed in the Visual Analogue Scale (VAS) and the Oswestry Disability Index (ODI) scores. No study reported postoperative neurological deficits although recurrence was observed in three out of the four studies; the recurrence cases required another surgery. Dural tear was the most common complication in all the patients in these 
Table 2. Studies with different modalities of treatment for rLDH and their outcome

\begin{tabular}{|c|c|c|c|c|c|c|}
\hline Author & Year & Study design & $\begin{array}{l}\text { Sample } \\
\text { size }\end{array}$ & $\begin{array}{l}\text { Mean } \\
\text { follow-up }\end{array}$ & Surgery done for rLDH & Outcome \\
\hline Jung et al. [14] & 2012 & Retrospective & 54 & $1-5 \mathrm{yr}$ & Open lumbar discectomy & Excellent in $54 \%$ \\
\hline Ahsan et al. [18] & 2012 & Prospective & 416 & $1-4 \mathrm{yr}$ & Discectomy & Satisfactory \\
\hline Albayrak et al. [23] & 2016 & Prospective & 70 & $1 \mathrm{mo}$ to $7 \mathrm{yr}$ & Microdiscectomy & All patients had good outcome \\
\hline Smith et al. [19] & 2010 & Retrospective & 16 & $14.7 \mathrm{mo}$ & Microendoscopic discectomy & Good to excellent in $80 \%$ \\
\hline Shin et al. [20] & 2011 & Retrospective & 41 & $16 \mathrm{mo}$ & $\begin{array}{l}\text { Percutaneous endoscopic discec- } \\
\text { tomy }\end{array}$ & Good to excellent in $90 \%$ \\
\hline Kim et al. [21] & 2012 & Prospective & 10 & $14.4 \mathrm{mo}$ & $\begin{array}{l}\text { Percutaneous endoscopic inter- } \\
\text { laminar discectomy }\end{array}$ & Good to excellent in $60 \%$ \\
\hline Hou et al. [22] & 2015 & Prospective & 25 & $3 \mathrm{yr}$ & Microendoscopic discectomy & Good to excellent in $96 \%$ \\
\hline Omidi-Kashani et al. [30] & 2014 & Retrospective & 51 & $31.4 \mathrm{mo}$ & TLIF & Good to excellent in $74.6 \%$ \\
\hline Li et al. [31] & 2015 & Prospective & 73 & $4.1 \mathrm{yr}$ & TLIF & $\begin{array}{l}\text { Mean recovery rate of Japa- } \\
\text { nese Orthopedic Association } \\
\text { score }=89 \%\end{array}$ \\
\hline El Kader [32] & 2016 & Retrospective & 15 & $24 \mathrm{mo}$ & TLIF & Good to excellent in $86 \%$ \\
\hline Sonmez et al. [33] & 2013 & Prospective & 20 & $24 \mathrm{mo}$ & $\begin{array}{l}\text { Unilateral vs. bilateral minimally } \\
\text { invasive surgery-TLIF }\end{array}$ & Both had same outcome \\
\hline El Shazly et al. [34] & 2013 & Prospective & 45 & $37 \mathrm{mo}$ & Discectomy vs. TLIF vs. PLIF & $\begin{array}{l}\text { TLIF and PLIF had comparable } \\
\text { result }\end{array}$ \\
\hline Pan et al. [39] & 2014 & Prospective & 35 & $16.8 \mathrm{mo}$ & Unilateral vs. bilateral TLIF & $\begin{array}{l}\text { Unilateral TLIF has advantage of } \\
\text { faster relief in back pain after } \\
\text { operation }\end{array}$ \\
\hline
\end{tabular}

rLDH, recurrent lumbar disc herniation; TLIF, transforaminal lumbar interbody fusion; PLIF, posterior lumbar interbody fusion.

four studies who were managed conservatively with good results. Minimal blood loss and early return to the work are the main advantages of this technique [19-22].

\section{3) Micro lumbar discectomy}

Albayrak et al. [23] reported on 71 patients who underwent MLD. Dural tear was noted in four patients (5\%). Considering the ODI scores of the patients during the follow-ups, a significant level of decline was observed $(p<0.001)$. None of the patients presented with iatrogenic instability in the 7-year follow-up period.

4) MLD with dynamic stabilization

A study by Kaner et al. [24] showed significant improvement in the ODI and VAS scores of patients who underwent dynamic stabilization. No recurrence was observed in their follow-up period. Two patients required revision surgery, one for foreign body reaction and the other for persistent symptoms [24].

5) Percutaneous endoscopic lumbar discectomy In his study on 43 patients that examined and compared the clinical results of percutaneous endoscopic lumbar discectomy (PELD) and open lumbar surgery for patients with adjacent segment degeneration and recurrence of disc herniation, Chen et al. [25] concluded that PELD had more advantages than open lumbar surgery in terms of reduced blood loss, shorter hospital stay, operating time, fewer complications, and less postoperative discomfort. Kim et al. [26] reported re-recurrence of $\mathrm{LDH}$ in 7\% patients treated with percutaneous endoscopic discectomy for $\mathrm{rDH}$ and reported the need for a third surgery.

\section{6) Fusion surgery}

Mini-open retroperitoneal ALIF is an effective treatment for patients with $\mathrm{rLDH}$ following primary posterior instrumentation, as reported by Mamuti et al. [27]. There was no neurological worsening, and radicular pain reduced significantly compared to that before the operation in all the patients. Computed tomography reconstruction at 12 and 24 months postoperatively showed bony fusion and normal cage position in all the patients. In their study, Mao et al. [28] used MIS-TLIF with hybrid fixation technique and achieved good results with a significant 
Table 3. Surgical techniques for recurrent lumbar disc herniation

\begin{tabular}{|c|c|c|}
\hline Surgical procedure & Advantages & Disadvantages \\
\hline Conventional discectomy $[14,18]$ & $\begin{array}{l}\text { Good relief } \\
\text { Easy to remove hidden fragments }\end{array}$ & $\begin{array}{l}\text { Dural tear } \\
\text { May require revision surgery }\end{array}$ \\
\hline Microendoscopic discectomy [19-22] & $\begin{array}{l}\text { Good to excellent outcome } \\
\text { Minimal blood loss } \\
\text { Early return to the work }\end{array}$ & $\begin{array}{l}\text { Dural tear } \\
\text { Steep learning curve }\end{array}$ \\
\hline MLD [22] & $\begin{array}{l}\text { Good relief in immediate postoperative period } \\
\text { Avoids need for fusion surgery }\end{array}$ & $\begin{array}{l}\text { Dural tear } \\
\text { Revision surgery }\end{array}$ \\
\hline MLD with dynamic stabilization [23] & $\begin{array}{l}\text { Decrease the risk of postoperative segmental } \\
\text { instability } \\
\text { Reduces the frequency of failed back syndrome }\end{array}$ & $\begin{array}{l}\text { Foreign body reaction } \\
\text { Low back pain and sciatica }\end{array}$ \\
\hline Percutaneous endoscopic lumbar discectomy $[19,24,26]$ & $\begin{array}{l}\text { Good to excellent outcome } \\
\text { Less blood loss } \\
\text { Shorter hospital stay } \\
\text { Shorter operative time }\end{array}$ & $\begin{array}{l}\text { Re-recurrence } \\
\text { Cerebrospinal fluid leak } \\
\text { Steep learning curve } \\
\text { Need for third surgery }\end{array}$ \\
\hline Fusion surgery $[29,30]$ & $\begin{array}{l}\text { No re-recurrence } \\
\text { Maintained disc space height } \\
\text { No postoperative back pain } \\
\text { Less dural and nerve injury } \\
\text { Reduced postoperative instability }\end{array}$ & $\begin{array}{l}\text { Loss of movements at fused segment } \\
\text { Adjacent segment degeneration }\end{array}$ \\
\hline
\end{tabular}

MLD, micro lumbar discectomy.

improvement in the VAS and ODI scores. Unilateral incision, less invasiveness, and quick recovery were the advantages of this method. Trabecular metal interbody fusion cages in a stand-alone fashion were used by Lequin et al. [29] in their study on 26 patients followed up for 1 year. Although only $46 \%$ of the patients reported good recovery with significant reductions in back and leg pain, $85 \%$ reported at least some benefit from the operation and a marked improvement in the working status [29].

Three studies reported on the outcomes of open TLIF for $\mathrm{rDH}$ [30-32]. Excellent to good results were noted in $74.6 \%-91.5 \%$ of the patients. Fusion rates were $100 \%$ in two studies and $93.2 \%$ in a third study. No instrument failures were reported. Dural lacerations with persistent cerebrospinal fluid leak were noted in all the studies. Partial neurological injury was reported in studies by Omidi-Kashani et al. [30] and Li et al. [31]. Three patients required revision surgery for adjacent level pathology [30,31]. Li et al. [31] compared endoscopic and open surgery in terms of fusion and concluded that both the operative methods can obtain good clinical results; however, TLIF using MED offers the advantages of lower trauma, less pain, and better functional recovery. Percutaneous minimally invasive TLIF has also been reported to have similar advantages when compared to open TLIF.

The paraspinal approach with unilateral pedicle screw fixation and TLIF has the advantages of smaller surgical incision, shorter operation time, less intra-operative blood loss, and faster postoperative relief from low back pain when compared to open bilateral screws for selected cases [33]. El Shazly et al. [34] compared decompression and fusion to find that fusion with revision discectomy reduces postoperative low back pain, decreases the intraoperative risk of dural tear or neural damage and decreases the postoperative incidence of mechanical instability or re-recurrence. TLIF and PLIF have comparable results when used with revision discectomy; however, PLIF has a significantly lower total cost than TLIF.

\section{Discussion}

rLDH is one of the major causes for failure of primary surgery [35]. The recurrence rates in the literature range from $0.5 \%-23 \%[1,2]$. This review aimed to summarize the current evidence on the risk factors and surgical strategies for rLDH.

Various risk factors have been reported in different studies. With regard to age, conflicting results were observed. Few studies reported increased risk in the people less than 40 years and some others reported in individuals more than 50 years [1-8]. The higher risk of recurrence in older patients is believed to be attributable to the greater 
disc degeneration in these patients than that in younger patients. The remaining nucleus pulposus fragment is more susceptible to herniate under the stimulus of mechanical overload caused by the annular incision generated during discectomy. In contrast, tall discs with more disc material and long postoperative period are reported as the risk factors for recurrence in young patients. Most articles have reported a higher risk in men [1,5-8,10,11].

Meredith et al. [8] reported that the mean BMI value of patients with herniation recurrence after successful lumbar microdiscectomy was significantly higher than that of those without herniation recurrence. The risk of recurrence can increase with obesity; therefore, the BMI value should be considered postoperatively, and weight management should be advised postoperatively $[1,6,8,12]$. Smoking is reported as a contributing factor in many pathological processes $[5,10]$. Smokers were more likely to experience $\mathrm{rLDH}$ when they undergo minimally invasive surgery. Many complications, such as wound healing and cardiopulmonary complications after elective orthopedic surgery are related to smoking. Few studies demonstrated that smoking has a significant correlation with recurrence.

Modic changes are changes in the vertebral body associated with inflammation, unstable microenvironment, and degenerative disc disease $[1,12]$. Kim et al. [21] have identified Modic changes as a risk factor for PELD recurrence; this finding was supported by Yao et al. [9] who concluded that the selection of the type of minimally invasive surgery (MED and PELD) should be well planned, and patients should be informed preoperatively of the relatively higher risk of recurrence. Yaman et al. [12] reported that Modic changes were more significant in the recurrence group than in those without recurrence. Lumbar disc protrusion without a herniated fragment or defect in the annulus was reported to have the highest risk of rLDH by Carragee et al. [36]. Recent studies have reported that a large annular defect is a risk factor for recurrence [7]. Sub ligamentous or caudal migration of disc material have been associated with higher recurrence rates [11].

Of the seven studies from the decompressive group, studies by Jung et al. [14] and Ahsan et al. [18] have reported good results with conventional discectomy alone. Trauma as an inciting event is associated with poor results in both the studies (Table 3). No instability was noted in the 7-year follow-up study by Albayrak et al. [23] that involved 70 patients who underwent MLD. No neurological deficits were reported in any of the studies although dural tear was the most commonly reported complication in all the papers. Minimal blood loss and early return to work are the main advantages highlighted in all studies on MED [19-22]. However, the presence of epidural scarring due to previous surgery makes minimally invasive surgeries challenging, with a steep learning curve being required to achieve comparable results. Epidural scar tissue handling should be performed with great care during separation from neural tissue. Meticulous epidural dissection around scar formation must be performed during revision surgery to avoid dural lacerations [37]. It is recommended that the epidural scar tissue not be dissected; a lateral approach should be used [38]. The amount of disc material to be removed in the second surgery remains debatable because aggressive removal may lead to collapse of the disc space and low back pain. Studies on non-fusion treatment options report the re-recurrence of $\mathrm{LDH}$, necessitating the third surgery. In view of re-recurrence of $\mathrm{LDH}$, a more suitable option may be to perform fusion surgery at the time of the second surgery [26].

Fusion surgeries are indicated in presence of chronic low back pain, features of instability of radiographs, and severe disc degeneration on magnetic resonance imaging. Fusion surgeries are known to reduce postoperative low back pain, decrease the intra-operative risk of dural tear or neural damage, and reduce the chances of rerecurrence or mechanical instability. Various fusion techniques have been reported with excellent to good clinical outcomes [26-28]. Minimally invasive fusion techniques, such as MIS-TLIF, with unilateral or bilateral fixation offer the advantages of lower blood loss, less invasion, and quick recovery; however, the overall long-term results seem comparable to those of the open group $[33,34,39,40]$.

The choice between revision discectomy and discectomy with fusion for rLDH has been a highly debated topic. Fusion surgeries usually involve a longer operative time, more blood loss, and longer stay compared to decompressive surgeries alone. However, fewer comparative studies make it challenging to conclude regarding the superiority of one technique over that of the other. In a comparative study by El Shazly et al. [34], fusion surgeries achieved greater reduction in low back pain and lower postoperative chances of mechanical instability or re-recurrence as well as intra-operative chances of dural tear.

Controversies exist in the literature about the treatment for $\mathrm{rDDH}$ using repeat discectomy procedures with regard to re-recurrence of the LDH. Better outcomes have been 
reported in cases where the selection of surgery type is based on patient factors before the first surgery and at the time of the present surgery, technical expertise of the surgeon for procedures, and removal of hidden fragments during the second surgery.

We conclude that many possible risk factors that are present before the primary surgery and persist in the post-surgical period may cause rLDH. These risk factors should be considered while planning the management of rLDH that can be managed with revision endoscopic surgery or MLD in most patients. These repeat discectomy procedures carry a risk of $\mathrm{LDH}$ re-recurrence. Fusion surgery achieves better outcome in patients with low back pain and associated instability. Both, bilateral and unilateral TLIF provide good outcome; unilateral TLIF gives faster relief from back pain in the postoperative period. MIS-TLIF gives equally good results in back and leg pain. The strategy to prevent rLDH includes the identification of all the possible reported risk factors associated with recurrence and choice of a suitable surgical procedure. The modification of lifestyle and other risk factors in the patients should also be considered after the primary surgery. Further randomized control studies and studies with long-term outcome are required to determine the optimal procedure for rLDH treatment.

\section{Conclusions}

Management of the rLDH requires consideration of the possible risk factors present in individual patients before primary surgery and at the time of the second surgery. Both, minimally invasive and conventional open procedures are equally effective in relieving leg pain; minimally invasive techniques offer advantages over the other technique in terms of tissue sparing. Non-fusion surgeries involve the risk of re-recurrence of $\mathrm{LDH}$ that would require a third (fusion) surgery.

\section{Conflict of Interest}

No potential conflict of interest relevant to this article was reported.

\section{References}

1. Aizawa T, Ozawa H, Kusakabe T, et al. Reoperation for recurrent lumbar disc herniation: a study over a 20-year period in a Japanese population. J Orthop Sci 2012;17:107-13.

2. Lebow RL, Adogwa O, Parker SL, Sharma A, Cheng J, McGirt MJ. Asymptomatic same-site recurrent disc herniation after lumbar discectomy: results of a prospective longitudinal study with 2-year serial imaging. Spine (Phila Pa 1976) 2011;36:2147-51.

3. Yurac R, Zamorano JJ, Lira F, Valiente D, Ballesteros V, Urzua A. Risk factors for the need of surgical treatment of a first recurrent lumbar disc herniation. Eur Spine J 2016;25:1403-8.

4. Chang HK, Chang HC, Wu JC, et al. Scoliosis may increase the risk of recurrence of lumbar disc herniation after microdiscectomy. J Neurosurg Spine 2016;24:586-91.

5. Shimia M, Babaei-Ghazani A, Sadat BE, Habibi B, Habibzadeh A. Risk factors of recurrent lumbar disk herniation. Asian J Neurosurg 2013;8:93-6.

6. Moliterno JA, Knopman J, Parikh K, et al. Results and risk factors for recurrence following single-level tubular lumbar microdiscectomy. J Neurosurg Spine 2010;12:680-6.

7. Kim KT, Lee DH, Cho DC, Sung JK, Kim YB. Preoperative risk factors for recurrent lumbar disk herniation in L5-S1. J Spinal Disord Tech 2015;28:E571-7.

8. Meredith DS, Huang RC, Nguyen J, Lyman S. Obesity increases the risk of recurrent herniated nucleus pulposus after lumbar microdiscectomy. Spine J 2010;10:575-80.

9. Yao $\mathrm{Y}$, Liu $\mathrm{H}$, Zhang $\mathrm{H}$, et al. Risk factors for the recurrent herniation after microendoscopic discectomy. World Neurosurg 2016;95:451-5.

10. Miwa S, Yokogawa A, Kobayashi T, et al. Risk factors of recurrent lumbar disk herniation: a single center study and review of the literature. J Spinal Disord Tech 2015;28:E265-9.

11. Matsumoto M, Watanabe K, Hosogane N, et al. Recurrence of lumbar disc herniation after microendoscopic discectomy. J Neurol Surg A Cent Eur Neurosurg 2013;74:222-7.

12. Yaman ME, Kazanci A, Yaman ND, Bas F, Ayberk G. Factors that influence recurrent lumbar disc herniation. Hong Kong Med J 2017;23:258-63.

13. Quah C, Syme G, Swamy GN, Nanjayan S, Fowler A, Calthorpe D. Obesity and recurrent intervertebral disc prolapse after lumbar microdiscectomy. Ann R Coll Surg Engl 2014;96:140-3. 
14. Jung YS, Choi HJ, Kwon YM. Clinical outcome and influencing factor for repeat lumbar discectomy for ipsilateral recurrent lumbar disc herniation. Korean J Spine 2012;9:1-5.

15. Teli M, Lovi A, Brayda-Bruno M, et al. Higher risk of dural tears and recurrent herniation with lumbar micro-endoscopic discectomy. Eur Spine J 2010;19:44350 .

16. Cheng J, Wang H, Zheng W, et al. Reoperation after lumbar disc surgery in two hundred and seven patients. Int Orthop 2013;37:1511-7.

17. Park JS, Choi SE, Cho TK, et al. Recurrence rate after herniotomy only versus discectomy in lumbar disc herniation. Korean J Spine 2013;10:227-31.

18. Ahsan K, Najmus-Sakeb, Hossain A, Khan SI, Awwal MA. Discectomy for primary and recurrent prolapse of lumbar intervertebral discs. J Orthop Surg (Hong Kong) 2012;20:7-10.

19. Smith JS, Ogden AT, Shafizadeh S, Fessler RG. Clinical outcomes after microendoscopic discectomy for recurrent lumbar disc herniation. J Spinal Disord Tech 2010;23:30-4.

20. Shin KH, Chang HG, Rhee NK, Lim KS. Revisional percutaneous full endoscopic disc surgery for recurrent herniation of previous open lumbar discectomy. Asian Spine J 2011;5:1-9.

21. Kim CH, Chung CK, Jahng TA, Yang HJ, Son YJ. Surgical outcome of percutaneous endoscopic interlaminar lumbar diskectomy for recurrent disk herniation after open diskectomy. J Spinal Disord Tech 2012;25:E125-33.

22. Hou T, Zhou Q, Dai F, et al. Repeated microendoscopic discectomy for recurrent lumbar disk herniation. Clinics (Sao Paulo) 2015;70:120-5.

23. Albayrak S, Ozturk S, Durdag E, Ayden O. Surgical management of recurrent disc herniations with microdiscectomy and long-term results on life quality: detailed analysis of 70 cases. J Neurosci Rural Pract 2016;7:87-90.

24. Kaner T, Sasani M, Oktenoglu T, Aydin AL, Ozer AF. Minimum two-year follow-up of cases with recurrent disc herniation treated with microdiscectomy and posterior dynamic transpedicular stabilisation. Open Orthop J 2010;4:120-5.

25. Chen HC, Lee CH, Wei L, Lui TN, Lin TJ. Comparison of percutaneous endoscopic lumbar discectomy and open lumbar surgery for adjacent segment de- generation and recurrent disc herniation. Neurol Res Int 2015;2015:791943.

26. Kim CH, Chung CK, Sohn S, Lee S, Park SB. The surgical outcome and the surgical strategy of percutaneous endoscopic discectomy for recurrent disk herniation. J Spinal Disord Tech 2014;27:415-22.

27. Mamuti M, Fan S, Liu J, et al. Mini-open anterior lumbar interbody fusion for recurrent lumbar disc herniation following posterior instrumentation. Spine (Phila Pa 1976) 2016;41:E1104-14.

28. Mao KY, Wang Y, Xiao SH, et al. A feasibility research of minimally invasive transforaminal lumbar interbody fusion (MIS-TLIF) using hybrid internal fixation for recurrent lumbar disc herniation. Zhonghua Wai Ke Za Zhi 2013;51:723-7.

29. Lequin MB, Verbaan D, Bouma GJ. Posterior lumbar interbody fusion with stand-alone Trabecular Metal cages for repeatedly recurrent lumbar disc herniation and back pain. J Neurosurg Spine 2014;20:617-22.

30. Omidi-Kashani F, Ghayem Hasankhani E, Noroozi HR. Instrumented transforaminal lumbar interbody fusion in surgical treatment of recurrent disc herniation. Med J Islam Repub Iran 2014;28:124.

31. Li Z, Tang J, Hou S, et al. Four-year follow-up results of transforaminal lumbar interbody fusion as revision surgery for recurrent lumbar disc herniation after conventional discectomy. J Clin Neurosci 2015;22:331-7.

32. El-Kader HE. Transforaminal lumbar interbody fusion for management of recurrent lumbar disc herniation. Asian Spine J 2016;10:52-8.

33. Sonmez E, Coven I, Sahinturk F, Yilmaz C, Caner H. Unilateral percutaneous pedicle screw instrumentation with minimally invasive TLIF for the treatment of recurrent lumbar disk disease: 2 years follow-up. Turk Neurosurg 2013;23:372-8.

34. El Shazly AA, El Wardany MA, Morsi AM. Recurrent lumbar disc herniation: a prospective comparative study of three surgical management procedures. Asian J Neurosurg 2013;8:139-46.

35. Kim KT, Park SW, Kim YB. Disc height and segmental motion as risk factors for recurrent lumbar disc herniation. Spine (Phila Pa 1976) 2009;34:2674-8.

36. Carragee EJ, Han MY, Suen PW, Kim D. Clinical outcomes after lumbar discectomy for sciatica: the effects of fragment type and anular competence. J Bone Joint Surg Am 2003;85:102-8. 
37. Inada T, Nishida S, Kawaoka T, Takahashi T, Hanakita J. Analysis of revision surgery of microsurgical lumbar discectomy. Asian Spine J 2018;12:140-6.

38. Acharya KN, Nathan TS, Kumar JR, Menon KV. Primary and revision lumbar discectomy: a three-year review from one center. Indian J Orthop 2008;42:17881.

39. Pan B, Fu CD, Ge YL, et al. Unilateral pedicle screw fixation and transforaminal lumbar interbody fusion through paraspinal muscle approach for recurrent lumbar disc herniation combined with lumbar instability. Zhongguo Gu Shang 2014;27:712-6.

40. Niesche M, Juratli TA, Sitoci KH, et al. Percutaneous pedicle screw and rod fixation with TLIF in a series of 14 patients with recurrent lumbar disc herniation. Clin Neurol Neurosurg 2014;124:25-31. 